\title{
Effect of Stress Hormone on Development of Diabetes Mellitus Type 2 Disease
}

\author{
Dr. Dina Ayed Mohammed \\ Ph.D. Clinical Biochemistry \\ Al-Nisour University College-Baghdad-Iraq \\ E-mail / alimsaleam@gmail.com \\ Mobile / 009647725503941
}

\begin{abstract}
Subject :Diabetes Mellitus (DM) is most common disease characterized by

elevation of serum glucose level due to impair insulin production called type $1 \mathrm{DM}$ or impair cell response to insulin called type 2 DM .Cortisol is the steroid hormone that secretion by adrenal gland and it's consider as stress hormone , act many important role in humane body such as regulation of immune system and metabolic process .

Objective of the Study: Role of cortisol in development of DM type 2 disease. Materials and Methods: This study was done on 30 patients with un-control DM type 2 patients and 30 control DM type 2 patients, the all subjects age within this study were more than 50 years of both genders.After obtained serum, immediately used quantity method for measured level of serum cortisol concentration .

Results: This study shows elevation of serum cortisol concentration level in uncontrol DM type 2 group compare with control DM type 2 group.

Conclusion: This study confirms that serum cortisol concentration level can act as support DM type 2 disease .

Keywords: depression ,cortisol and DM.
\end{abstract}




\section{Introduction}

Diabetes mellitus (DM) is a chronic disease characterized by elevation of blood glucose level that occurs when the pancreas is unable to produce enough insulin, called type $1 \mathrm{DM}$, it occurs in children, or when the body is unable to effectively use the insulin it produces, called type $2 \mathrm{DM}$, it occurs in the old age . Insulin is a hormone that controls the level of glucose in the serum. Hyperglycemia, also known as high blood sugar, is a common finding of poor blood sugar control (1) . Over time, diabetes can have harmful effect on some of body organs such as the heart, blood vessels, eyes, kidneys, and nerves. There are many symptoms and signs that diabetics suffer from, such as excessive thirst, frequent night urination, low weight and other symptoms of others. Diabetes is diagnosed by several tests, the most important of these tests are checking the level of fasting blood sugar, glycated hemoglobin and other tests (2).

Cortisol is one of the corticosteroids produced by the adrenal cortex. The hormone is transported from the adrenal gland to all parts of the body through the blood, where it affects almost all cells of the body. The effects of cortisol in cells include: regulating blood sugar levels, regulating metabolism, anti-inflammatory, stress response, and other functions (3). The secretion of cortisol is mainly controlled by three important centers in the body which are the hypothalamus in the brain, the pituitary gland and the adrenal gland; When the level of cortisol in the blood decreases, the hypothalamus cells become alert and secrete corticotropin-releasing hormone, which in turn stimulates the pituitary gland's secretion of adrenocorticotropic hormone, which stimulates the adrenal glands to produce cortisol and thus its secretion into the blood. It should be noted that cortisol levels in the blood vary greatly, reaching their highest level in the early morning after waking up, and then gradually decreasing throughout the day (4) .

\section{Materials and Methods}

This study involved 60 subjects ,classified into 30 cases with un-control DM type 2 disease , and 30 cases with control DM type 2 disease, all subjects age was 50 years and above of both genders, and subjects selected from Al-Yarmouk Teaching Hospital - Iraq . This study focused on psychological state of all individuals when selection. The collection of blood sample of all individuals were done via separation the blood sample immediately without any preservative factors to obtain pure serum for measurement of cortisol level at P.M. period by TOSOH instrument (automated tool).

Statistic analysis in current study was use the t-test method to show different in cortisol level between un-control and control groups of DM type 2 cases. The t-test method used mean \pm standard deviation $(\mathrm{SD})$ and $\mathrm{p}$-value ( $>0.05$ significant value ) . 


\section{Results}

The current study presented compare between two groups (un-control and control DM type 2 cases ) according to blood cortisol level, where showed significant different between two groups by used mean \pm SD statistic method. Serum cortisol level in un-control group was $8.1 \pm 1.06$, while in control group was $5.6 \pm 0.91$ with Pvalue was 0.032 . This study emphasize increase of serum cortisol level at P.M. period in un-control group of DM type 2 compared with control group of DM type 2 .Show table 1.

Table 1: Comparison of serum cortisol level between un-control and control groups of DM type 2 cases according to mean \pm standard deviation $(S D)$

\begin{tabular}{|l|l|l|l|}
\hline Parameters & $\begin{array}{l}\text { Un-control } \\
\text { group of DM } \\
\text { type2 (No.=30) } \\
\text { Mean+SD }\end{array}$ & $\begin{array}{l}\text { Control group } \\
\text { of DM type2 } \\
\text { (No. =30) } \\
\text { Mean+SD }\end{array}$ & P-value \\
\hline $\begin{array}{l}\text { Cortisol level } \\
(\mathrm{ng} / \mathrm{ml})\end{array}$ & $8.1 \pm 1.06$ & $5.6 \pm 0.91$ & $0.032^{*}$ \\
\hline
\end{tabular}

*Significant value

\section{Discussion}

DM is one of the most commonly chronic disease in population, its has many complication that effect on physiological body systems such as effect on renal, eyes and neurons. These harmful effects of DM disease already can support and stimulate worry feeling for patients these felling can called psychiatric stress .The patients stress can convert to depression when DM patient being more worry about his healthy, already the depression felling can start to stimulate the stress hormones , commonly is cortisol hormone that consider as primary stress hormone $(2,4)$.

The cortisol hormone is steroid hormone product and release by some of adrenal gland layers with a diurnal cycle manner, it play role in many functions in body such as regulation of immune response, blood pressure and bio-molecular metabolisms(5) . The effect of cortisol hormone on regulation of bio-molecular metabolisms shown in many of metabolic pathway, commonly pathway is stimulate liver and muscle glycogenolysis and gluconeogenesis which occurs as a result of the 
action of cortisol . Glycogenolysis and gluconeogenesis are metabolic processes lead to increase of serum glucose level that can development of DM severity then lead to un-control serum glucose level (6) .

The present study results confirm elevation of serum cortisol level in un-control DM type 2 patients who suffer of depression when compared with control DM type 2 patients . This study agree with Joseph JJ, and et al 2017 that documented the linear correlation between blood cortisol level, depression and DM disease (7) .

\section{Conclusion}

This study concluded that patients with un-control DM type 2 suffer of depression that lead to increase cortisol level, in this situation become difficult control on DM disease.

\section{References}

1- Yaribeygi H, Sathyapalan T, Atkin SL, Sahebkar A. Molecular mechanisms linking oxidative stress and diabetes mellitus. Oxidative medicine and cellular longevity. 2020 Mar 9;2020.

2- Wieringa TH, de Wit M, Twisk JW, Snoek FJ. Improving interpretability of individual Diabetes Symptom Checklist-Revised (DSC-R) scores: the role of patient characteristics. BMJ Open Diabetes Research and Care. 2020 Apr 1;8(1):e001146.

3- Drummond JB, Soares BS, Pedrosa W, Ribeiro-Oliveira A. Revisiting peak serum cortisol response to insulin-induced hypoglycemia in children. Journal of Endocrinological Investigation. 2021 Jun;44(6):1291-9.

4- Basu A, Yadav Y, Carter RE, Basu R. Novel Insights Into Effects of Cortisol and Glucagon on Nocturnal Glucose Production in Type 2 Diabetes. The Journal of Clinical Endocrinology \& Metabolism. 2020 Jul 1;105(7):e237888.

5- Prete A, Taylor AE, Bancos I, Smith DJ, Foster MA, Kohler S, FazalSanderson V, Komninos J, O’Neil DM, Vassiliadi DA, Mowatt CJ. Prevention of adrenal crisis: cortisol responses to major stress compared to stress dose hydrocortisone delivery. The Journal of Clinical Endocrinology \& Metabolism. $2020 \mathrm{Jul} ; 105(7): 2262-74$.

6- Dias JP, Joseph JJ, Kluwe B, Zhao S, Shardell M, Seeman T, Needham BL, Wand GS, Kline D, Brock G, Castro-Diehl C. The longitudinal association of changes in diurnal cortisol features with fasting glucose: MESA. Psychoneuroendocrinology. 2020 Sep 1;119:104698. 
7- Joseph JJ, Golden SH. Cortisol dysregulation: the bidirectional link between stress, depression, and type 2 diabetes mellitus. Annals of the New York Academy of Sciences. 2017 Mar;1391(1):20. 